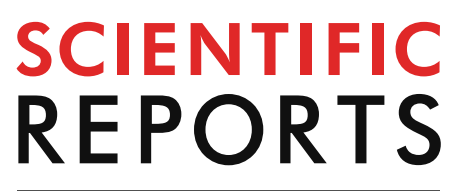

natureresearch

Check for updates

\title{
Iron biofortification and availability in the mycelial biomass of edible and medicinal basidiomycetes cultivated in sugarcane molasses
}

\author{
Simone Schenkel Scheid ${ }^{1}$, Maria Graciela lecher Faria ${ }^{1}$, Leonardo Garcia Velasquez ${ }^{2}$, \\ Juliana Silveira do Valle ${ }^{1}$, Affonso Celso Gonçalves Jr. ${ }^{3}$, Douglas Cardoso Dragunski ${ }^{4}$, \\ Nelson Barros Colauto ${ }^{1}$ \& Giani Andrea Linde ${ }^{1 \bowtie}$
}

Basidiomycetes can bioaccumulate high iron contents, but there are few studies on iron availability from the mycelial biomass in order to support their use as an iron-enriched fungal food. This study aimed to evaluate the in vitro iron bioaccumulation and availability in the mycelial biomass of edible and medicinal basidiomycetes grown in two distinct culture media. Lentinus crinitus, Ganoderma lucidum, Schizophyllum commune, Pleurotus ostreatus, Pleurotus eryngii, Lentinula edodes, and Agaricus subrufescens were grown in liquid culture medium of malt extract or sugarcane molasses to obtain iron-bioaccumulated mycelial biomass. $P$. ostreatus was the fungus that most bioaccumulated iron, followed by $S$. commune, and $P$. eryngii; they also had the highest mycelial biomass growth and iron transfer from the culture medium to the mycelial biomass. Mycelial iron availability is speciesspecific, regardless of the culture medium and the iron bioaccumulation capacity of the fungus in the mycelial biomass. Mycelial biomass of $S$. commune, followed by $G$. lucidum, P. ostreatus, and $P$. eryngii, associated with molasses culture medium, are the best choice for the production of ironenriched mycelial biomass.

Iron is an essential metal for animal metabolism as it is involved in DNA synthesis, hemoglobin, and redox reactions ${ }^{1}$. The most recent report from the World Health Organization (WHO) estimated that around 1.62 billion people, mainly children and women, had iron deficiency anemia ${ }^{2}$ and considered it a global public health problem of epidemic proportions ${ }^{3}$. Besides anemia, iron deficiency causes other abnormalities such as deficiency of vitamin B12 and vitamin A, parasitic infections, chronic inflammation, and inherited disorders ${ }^{4}$. Moreover, in 2012, the WHO established a global nutrition target for 2025: "achieving a 50\% reduction of anemia in women

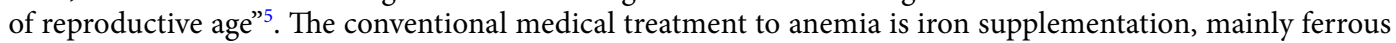
sulfate, which is a strong pro-oxidant that has been related to chronic diseases such as cirrhosis, cardiovascular diseases, type- 2 diabetes, and cancer when in excess ${ }^{6,7}$. Therefore, the conventional treatment of anemia may cause a health issue, and iron food fortification seems to be a favorable risk-benefit ratio to improve health and prevent some diseases.

Basidiomycetes can bioaccumulate metals of nutritional and pharmacological importance such as iron ${ }^{8-10}$, zinc $^{10,11}$, selenium ${ }^{12}$, and lithium ${ }^{13,14}$. Vegetative mycelial biomass of some basidiomycetes are reported to present iron content of $3,616 \mathrm{mg} \mathrm{kg}^{-1}$ in Pleurotus ostreatus ${ }^{8}$ and $2,595 \mathrm{mg} \mathrm{kg}^{-1}$ in Agaricus subrufescens ${ }^{10}$. Therefore, the mycelial biomass of edible and medicinal basidiomycetes could be a source of several metals, such as iron, besides natural bioactive molecules. For instance, in order to meet an adult woman's daily need of $18 \mathrm{mg}$ iron ${ }^{15}$, an intake of 5-g mycelial-bioaccumulated iron $\left(3,616 \mathrm{mg} \mathrm{kg}^{-1}\right.$ iron in mycelial biomass) would be sufficient ${ }^{8}$. However, these authors did not consider the iron availability in the mycelial biomass. Determining the iron availability is important to indicate the metal-absorption capacity by an organism, according to the iron solubility level ${ }^{2,3,6}$.

${ }^{1}$ Graduate Program of Biotechnology Applied to Agriculture, Universidade Paranaense, Mascarenhas de Moraes, 4282, Umuarama, PR 87502-210, Brazil. 'Medicinal Plants and Herbal Remedies in Basic Care, Universidade Paranaense, Umuarama, PR, Brazil. ' ${ }^{3}$ Laboratory of Environmental Chemistry, Centre of Agricultural Science, West Paraná State University, Marechal Cândido Rondon, PR, Brazil. ${ }^{4}$ Center of Engineering and Exact Sciences, West Paraná State University, Toledo, PR, Brazil. ${ }^{\bowtie}$ email: gianilinde@prof.unipar.br 


\begin{tabular}{|c|c|c|c|}
\hline Effect & F & df & $\mathbf{P}$ \\
\hline \multicolumn{4}{|l|}{ Mycelial biomass growth } \\
\hline Species & 382.0 & 6.42 & $<0.001$ \\
\hline Culture-medium & 204.0 & 1.42 & $<0.001$ \\
\hline Species $\times$ culture-medium & 143.2 & 6.42 & $<0.001$ \\
\hline \multicolumn{4}{|c|}{ Iron content in the mycelial biomass } \\
\hline Species & 108.3 & 6.42 & $<0.001$ \\
\hline Culture-medium & $2,126.3$ & 1.42 & $<0.001$ \\
\hline Species $\times$ culture-medium & 102.4 & 6.42 & $<0.001$ \\
\hline \multicolumn{4}{|c|}{$\begin{array}{l}\text { Iron transfer from the culture medium to the mycelial } \\
\text { biomass }\end{array}$} \\
\hline Species & 177.5 & 6.42 & $<0.001$ \\
\hline Culture-medium & 1675.4 & 1.42 & $<0.001$ \\
\hline Species $\times$ culture-medium & 150.0 & 6.42 & $<0.001$ \\
\hline \multicolumn{4}{|c|}{ Solubilized iron from the mycelial biomass } \\
\hline Species & 70.8 & 6.42 & $<0.001$ \\
\hline Culture-medium & $1,464.0$ & 1.42 & $<0.001$ \\
\hline Species $\times$ culture-medium & 50.5 & 6.42 & $<0.001$ \\
\hline \multicolumn{4}{|c|}{ Iron availability from the mycelial biomass } \\
\hline Species & 468.4 & 6.42 & $<0.001$ \\
\hline Culture-medium & 0.82 & 1.42 & 0.370 \\
\hline Species $\times$ culture-medium & 2.0 & 6.42 & 0.076 \\
\hline \multicolumn{4}{|l|}{ Overall iron yield } \\
\hline Species & 138.9 & 6.42 & $<0.001$ \\
\hline Culture-medium & $1,198.6$ & 1.42 & $<0.001$ \\
\hline Species $\times$ culture-medium & 92.6 & 6.42 & $<0.001$ \\
\hline
\end{tabular}

Table 1. Effects of two-way analysis of variance (ANOVA).

Yokota and coworkers ${ }^{9}$ had determined the in vitro iron availability in P. ostreatus basidiocarps; however, they did not study the metal bioaccumulation in the mycelial biomass that is capable of higher metal-accumulation than the basidiocarp ${ }^{8,9}$. Thus, the aim of this study was to evaluate the in vitro iron bioaccumulation and availability in the mycelial biomass of edible and medicinal basidiomycetes grown in two distinct culture media.

\section{Results}

The two-way variance analysis showed significant effects of species and culture-medium on mycelial biomass growth, iron content in the mycelial biomass, iron transfer from culture medium to the mycelial biomass, solubilized iron from the mycelial biomass, iron availability from the mycelial biomass, and overall iron yield (Table 1).

Mycelial biomass cultivation. The mycelial biomass growth in culture medium of malt-extract ranged from 1.1 to $4.3 \mathrm{mg} \mathrm{mL}^{-1}$, and in sugarcane-molasses varied from 0.6 to $5.6 \mathrm{mg} \mathrm{mL}^{-1}$ (Fig. 1A). A two-way analysis of variance (ANOVA) showed significant differences between species and between culture-medium in biomass production (Table 1). Significant interaction of factors (species $\times$ culture-medium) was also registered due to the opposite effect of the culture-medium on the mycelial biomass of certain species. The highest $(p \leq 0.05)$ mycelial biomass growth was for S. commune in sugarcane-molasses culture medium (Fig. 1A). A. subrufescens and $L$. crinitus had mycelial biomass growth reduced by 1.5 and 1.97-fold, respectively, when cultivated in sugarcane-molasses culture medium. However, G. lucidum, S. commune, P. ostreatus, P. eryngii, and L. edodes mycelial biomass growth increased in sugarcane-molasses culture medium by 1.16, 2.00, 1.33, 2.31, and 1.42fold, respectively, compared with the growth in malt-extract culture medium (Supplementary Information 1).

Iron content in the mycelial biomass. The iron content of the mycelial biomass grown in culture medium of malt-extract ranged from 106 to $213 \mathrm{mg} \mathrm{kg}^{-1}$, and sugarcane-molasses ranged from 358 to $1,304 \mathrm{mg} \mathrm{kg}^{-1}$ (Fig. 1B). The iron content in the biomass on molasses were from 1.68 to 6.84 -fold higher than the ones on malt-extract. Two-way ANOVA showed significant $(p<0.001)$ increase of iron content in the mycelial biomass on molasses compared to malt-extract for all fungi, and significant $(p<0.001)$ differences between species were also revealed (Table 1). The lowest $(p \leq 0.05)$ values for iron in the mycelial biomass were for L. edodes, followed by L. crinitus, P. eryngii, and A. subrufescens (Fig. 1B). The highest $(p \leq 0.05)$ iron content was $1,304 \mathrm{mg} \mathrm{kg}^{-1}$ for $P$. ostreatus on molasses, and this value was $2.9,4.4,5.4$, and 12.5-fold higher than spinach, asparagus, shiitake, and broccoli, respectively (Table 2). In general, all fungi on molasses had greater iron content than vegetables (Fig. 1B, Table 2). 

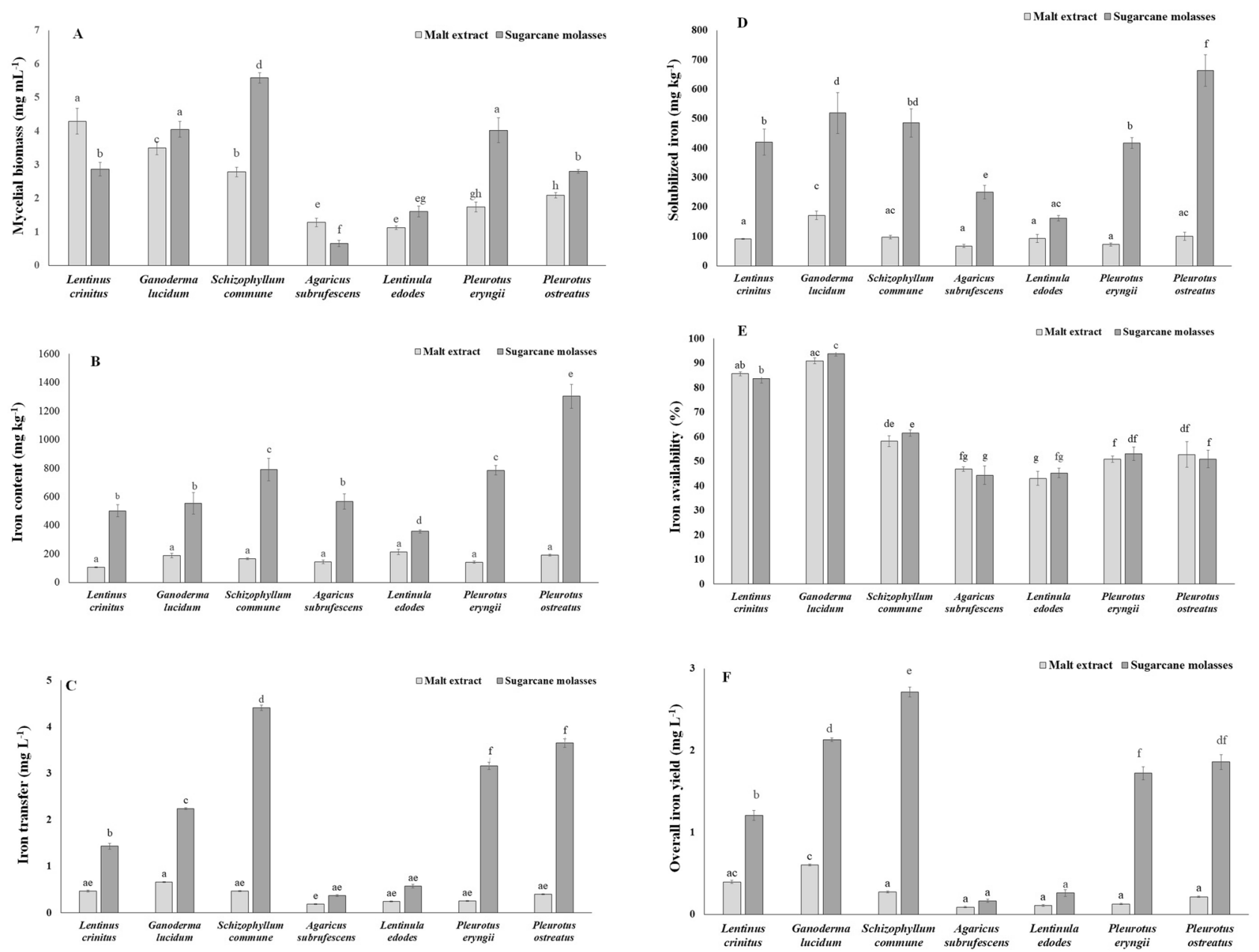

Figure 1. Mycelial biomass concentration (A), iron content in the mycelial biomass (B), iron transfer from culture medium to the mycelial biomass (C), solubilized iron from the mycelial biomass (D), iron availability from the mycelium biomass (E), and overall iron yield (soluble iron amount per liter of culture medium) (F) of basidiomycetes grown in liquid culture medium of malt-extract or sugarcane molasses for 21 days. Maltextract culture medium: $60.00 \mathrm{mg} \mathrm{L}^{-1}$ nitrogen, $19.14 \mathrm{~g} \mathrm{~L}^{-1}$ carbohydrate, $0.116 \mathrm{mg} \mathrm{L}^{-1}$ iron, and $260.00 \mu \mathrm{g} \mathrm{L}^{-1}$ magnesium; sugarcane molasses culture medium: $120.00 \mathrm{mg} \mathrm{L}^{-1}$ nitrogen, $16.72 \mathrm{~g} \mathrm{~L}^{-1}$ carbohydrate, $91.23 \mathrm{mg} \mathrm{L}^{-1}$ iron, and $903.12 \mu \mathrm{g} \mathrm{L}{ }^{-1}$ magnesium. Different letters indicate differences among data by Tukey's HSD test $(p \leq 0.05)$.

\begin{tabular}{|l|l|l|l|}
\hline Vegetable/mushroom (scientific name) & Iron content $\left(\mathbf{m g ~ k g}^{-\mathbf{1}}\right)$ & Solubilized iron $\left(\mathbf{m g ~ k g}^{-\mathbf{1}}\right)$ & Iron availability $(\%)$ \\
\hline Asparagus (Asparagus officinalis) & $293.63 \pm 38.24^{\mathrm{b}}$ & $142.37 \pm 5.73^{\mathrm{b}}$ & $48.48 \pm 5.19^{\mathrm{b}}$ \\
\hline Broccoli (Brassica oleracea) & $104.08 \pm 6.75^{\mathrm{c}}$ & $26.03 \pm 1.54^{\mathrm{c}}$ & $25.01 \pm 2.48^{\mathrm{c}}$ \\
\hline Spinach (Spinacia oleracea) & $449.27 \pm 53.11^{\mathrm{a}}$ & $235.6 \pm 9.28^{\mathrm{a}}$ & $52.44 \pm 7.84^{\mathrm{a}}$ \\
\hline Shiitake (Lentinula edodes) & $239.92 \pm 24.37^{\mathrm{b}}$ & $128.26 \pm 10.16^{\mathrm{b}}$ & $53.46 \pm 4.10^{\mathrm{a}}$ \\
\hline
\end{tabular}

Table 2. Iron content and availability of vegetables and shiitake basidiocarp. Different letters indicate statistical differences among data in the same row by Tukey's HSD test $(p \leq 0.05)$.

Iron transfer from the culture medium to the mycelial biomass. A two-way ANOVA showed significant $(p<0.001)$ increase of iron transfer from the culture-medium to the mycelial biomass on molasses compared to malt-extract for all fungi, and significant $(p<0.001)$ differences between species were also revealed (Table 1). The iron transfer was from 2.05 and 12.64-fold higher for all fungi cultivated in the molasses culture medium. The iron transfer from the culture-medium to the mycelial biomass takes into consideration the mycelial biomass production as well as the iron content in the mycelial biomass. The highest value was for $S$. commune, followed by P. ostreatus, and P. eryngii (Fig. 1C). Although S. commune did not have the highest iron 
content in the mycelial biomass (Fig. 1B), it had great mycelial biomass growth on molasses (Fig. 1A). Thus, $S$. commune on molasses was the most efficient to transfer iron from the culture medium to the mycelial biomass.

Solubilized iron from the mycelial biomass. A two-way ANOVA showed significant $(p<0.001)$ increase on iron solubilized for mycelial biomass on molasses compared to malt-extract for all fungi, and significant $(p<0.001)$ differences between species were also revealed (Table 1$)$. The highest $(p \leq 0.05)$ solubilized iron value was $663 \mathrm{mg} \mathrm{kg}^{-1}$ for $P$. ostreatus on molasses, and the lowest $(p \leq 0.05)$ one was $161 \mathrm{mg} \mathrm{kg}^{-1}$ for L. edodes (Fig. 1D). The solubilized iron from the mycelial biomass cultivated on molasses ranged from 1.76 to 6.57 -fold higher than the ones cultivated on malt-extract. The highest solubilized iron (1,304 mg kg-1 iron) from fungi was 2.8, 4.7, 5.2, and 25.5-fold higher than spinach, asparagus, shiitake, and broccoli, respectively (Table 2).

Iron availability from the mycelial biomass. A two-way ANOVA showed significant $(p<0.001)$ increase of iron availability just between species $(p<0.001)$ (Table 1$)$. Iron availability of the mycelial biomass grown in malt-extract or molasses was similar and ranged from 43 to $91 \%$, and from 44 to $94 \%$, respectively. The greatest $(p \leq 0.05)$ iron availability values were for G. lucidum and the lowest $(p \leq 0.05)$ ones for L. edodes and A. subrufescens (Fig. 1E). The iron availability is a species-specific fungal feature, regardless of the culture medium and the fungal capacity of iron bioaccumulation in the mycelial biomass (Fig. 1E). The iron availability from $G$. lucidum mycelial biomass was 1.7, 1.8, 1.9, and 3.7-fold higher than shiitake, spinach, asparagus, and broccoli, respectively (Table 2 ).

Overall iron yield. The overall iron yield was obtained by multiplying the mycelial biomass, iron content in the mycelial biomass, and iron availability from the mycelial biomass for each fungal strain. This yield provides information on which fungus has the highest amount of soluble iron per liter of culture medium, which is an important parameter for the production of iron-enriched mycelial biomass. A two-way ANOVA showed significant $(p<0.001)$ increase of overall iron yield in the mycelial biomass on molasses compared to malt-extract for all fungi, and significant $(p<0.001)$ differences between species were also revealed (Table 1$)$. The mycelial biomass of $S$. commune, followed by G. lucidum, P. ostreatus, and P. eryngii, cultivated on molasses had higher $(p \leq 0.05)$ capacity to transfer and solubilize iron (Fig. $1 F)$. These fungal strains cultivated on molasses are the best choice for the production of iron-enriched mycelial biomass.

\section{Discussion}

The molasses culture medium was the best option to produce iron-enriched mycelial biomass because it had high iron bioaccumulation in the mycelial biomass, and high mycelial biomass growth. Molasses is a viscous liquid byproduct from sugar production containing predominantly hexose, sucrose, and proteins ${ }^{16}$. It is estimated that, in 2019, Brazil produced 622 million tons of sugarcane (Saccharum officinarum L.) generating about 37 million tons of molasses ${ }^{17}$. Molasses is sold at US $\$ 60 /$ ton and could be an alternative to malt extract sold at US \$149-298/ ton $^{16}$ to produce iron-enriched mycelial biomass from nutraceutical basidiomycetes.

In our study, sugarcane molasses medium increased the iron content in the mycelial biomass from 1.7 to 6.8-folds; this may be related to the high iron content usually found in molasses that was 787-fold higher than in malt-extract. Almeida and coworkers ${ }^{8}$ showed-through a central composite design-that the iron content in the culture medium was the most important factor for the iron bioaccumulation in P. ostreatus mycelial biomass. The increase in the iron bioaccumulation is related to the high iron content in the culture medium for $A$. subrufescens ${ }^{10}$ and P. ostreatus ${ }^{18}$ mycelial biomass, and P. ostreatus basidiocarp ${ }^{9}$. Fungi have several strategies to bind iron from the culture medium such as acidification of the culture medium, conversion of ferric to ferrous iron, and secretion of iron chelating molecules as hydroxamates ${ }^{19}$. Thus, iron content in the culture medium is the most relevant factor for ion bioaccumulation in the mycelial biomass of basidiomycetes.

There are few reports on the in vitro iron availability for basidiomycetes. For Yokota et al. ${ }^{9}$, in vitro hydrolysis of $P$. ostreatus basidiocarp solubilized iron was $161.2 \mathrm{mg} \mathrm{kg}^{-1}$ iron. This value is fourfold lower than the same P. ostreatus strain used in our study $\left(663.4 \mathrm{mg} \mathrm{kg}^{-1}\right.$ iron). We also verified that G. lucidum mycelial biomass presented higher solubilized iron than the other basidiomycetes. Haneef et al. ${ }^{20}$ reported that the $P$. ostreatus hyphae diameter is larger than the G. lucidum one. This suggests that G. lucidum mycelial biomass has a greater contact area in the in vitro hydrolysis process, which could improve iron solubilization during in vitro hydrolysis. Moreover, Haneef et al. ${ }^{20}$ verified that G. lucidum showed a greater amount of lipids, whereas P. ostreatus mycelial biomass showed relatively more polysaccharides and chitin. Polysaccharides are macromolecules that physically and chemically can bind iron, reducing its solubility during in vitro hydrolysis. Kim et al. ${ }^{21}$ tested the production of meat analogues utilizing A. bisporus mycelium with better umami taste and textural properties compared to meat analogues of soy protein. This indicates that most basidiomycetes, considered health foods, can be used to bioaccumulate iron in the mycelial biomass as an alternative for the production of iron-enriched functional foods, including meat analogues. In addition, sugarcane molasses, a sugar-crystallization byproduct, is an economic alternative to produce biotechnological biofortified food.

\section{Conclusion}

The fungi that most bioaccumulated iron are P. ostreatus, followed by S. commune, and P. eryngii; they also have the greatest mycelial biomass growth and iron transfer from the culture medium to the mycelial biomass. The mycelial iron availability is species-specific, regardless of the culture medium and the iron bioaccumulation capacity of the fungus in the mycelial biomass. The mycelial biomass of S. commune, followed by G. lucidum, $P$. ostreatus, and P. eryngii, associated with molasses culture medium, are the best choice for the production of iron-enriched mycelial biomass. 


\section{Methods}

Biological material. Lentinus crinitus (L.) Fr. (U9-1), Ganoderma lucidum (Curtis) P.Karst. (U12-6), Schizophyllum commune Fr. (U6-7), Pleurotus ostreatus (Jacq.) P.Kumm. (U2-9), Pleurotus eryngii (DC.) Quél. (U125), Lentinula edodes (Berk.) Pegler (U6-1), and Agaricus subrufescens Peck (U7-1), also referred to as Agaricus blazei Murrill or Agaricus brasiliensis Wasser et al., were from the culture collection of the Molecular Biology Laboratory of Paranaense University. All strains were registered in the National System of Genetic Patrimony Management and Associated Traditional Knowledge (SisGen, its acronym in Portuguese) under the number A04E776. The mycelia were grown in $20 \mathrm{~g} \mathrm{~L}^{-1}$ malt-extract agar (MEA), previously autoclaved at $121{ }^{\circ} \mathrm{C}$ for $20 \mathrm{~min}$, in the dark, at $28 \pm 1^{\circ} \mathrm{C}$. Homogenous mycelia without sectoring from the colony edge were used as inoculum for the assays.

Mycelial biomass cultivation. The mycelial biomass has grown in two distinct liquid culture media: maltextract and sugarcane molasses. Malt-extract is a standard culture medium for basidiomycetes, and sugarcane molasses is a byproduct of the sugar and ethanol industry, commonly used for the mycelial biomass growth of basidiomycetes to produce biomolecules and/or enzymes ${ }^{22,23}$. In an Erlenmeyer flask $(250 \mathrm{~mL}), 150 \mathrm{~mL}$ culture medium at $20 \mathrm{~g} \mathrm{~L}^{-1}$ malt-extract or sugarcane molasses was autoclaved at $121^{\circ} \mathrm{C}$ for $20 \mathrm{~min}$. The malt-extract culture medium consisted of $60.00 \pm 4.18 \mathrm{mg} \mathrm{L}^{-1}$ nitrogen, $19.14 \pm 5.16 \mathrm{~g} \mathrm{~L}^{-1}$ carbohydrate, $0.116 \pm 0.01 \mathrm{mg} \mathrm{L}^{-1}$ iron, and $260.00 \pm 0.28 \mu \mathrm{g} \mathrm{L}^{-1}$ magnesium. The sugarcane-molasses culture medium consisted of $120.00 \pm 1.85 \mathrm{mg} \mathrm{L}^{-1}$ nitrogen, $16.72 \pm 0.48 \mathrm{~g} \mathrm{~L}^{-1}$ carbohydrate, $91.23 \pm 0.001 \mathrm{mg} \mathrm{L}^{-1}$ iron, and $903.12 \pm 0.001 \mu \mathrm{g} \mathrm{L}{ }^{-1}$ magnesium. Each Erlenmeyer flask was inoculated with three $0.5 \mathrm{~mm}$ diameter MEA disks containing mycelia. The mycelial biomass has grown at $28 \pm 1{ }^{\circ} \mathrm{C}$ for 21 days, in the dark, without agitation, and separated by centrifugation at $2,900 \mathrm{~g}$ for $5 \mathrm{~min}$ at $4{ }^{\circ} \mathrm{C}$, washed three times, and dried in an air circulation oven at $60{ }^{\circ} \mathrm{C}$, until constant mass. Also, fresh vegetables (controls) from the local market such as asparagus (Asparagus officinalis L.), broccoli (Brassica oleracea L.), and spinach (Spinacia oleracea L.) were dried in an air circulation oven at $60^{\circ} \mathrm{C}$, until constant mass. The dried materials were ground in a mortar, and the granulometry was standardized in particles smaller than $44 \mu \mathrm{m}$.

Iron solubilized by enzymatic hydrolysis. The dried and ground ( $250 \mathrm{mg})$ samples (mycelial or vegetable biomass) were mixed to $15 \mathrm{~mL}$ ultrapure water, homogenized in a Vortex agitator, and the $\mathrm{pH}$ adjusted to 2 with $5 \mathrm{M} \mathrm{HCl}$. Then, $0.75 \mathrm{~mL}$ pepsin $\left(20 \mathrm{~g} \mathrm{~L}^{-1}\right)$, previously prepared in $0.1 \mathrm{M} \mathrm{HCl}$, was added and the mixture kept at $37{ }^{\circ} \mathrm{C}$, at $200 \mathrm{rpm}$, in an incubator shaker, for an hour. The mixture had $\mathrm{pH}$ adjusted to six with $1 \mathrm{M}$ $\mathrm{NaHCO}_{3}$, addition of $3.75 \mathrm{~mL}$ pancreatin solution $\left(8.6 \mathrm{~g} \mathrm{~L}^{-1}\right.$ biliary extract and $1.4 \mathrm{~g} \mathrm{~L}^{-1}$ pancreatin prepared in $\left.0.1 \mathrm{M} \mathrm{NaHCO}_{3}\right), \mathrm{pH}$ adjusted again to seven with $1 \mathrm{M} \mathrm{NaOH}$, addition of $5 \mathrm{~mL} \mathrm{NaCl}(120 \mathrm{mM}), 5 \mathrm{~mL} \mathrm{KCl}$ $(5 \mathrm{mM})$, and incubated at $37^{\circ} \mathrm{C}$, at $200 \mathrm{rpm}$, for an hour. After enzyme digestion, the mixture was centrifuged at $15,300 \mathrm{~g}$ for $10 \mathrm{~min}$ at $4^{\circ} \mathrm{C}$, and the clear supernatant and the precipitate were dried in an air circulation oven at $60^{\circ} \mathrm{C}$ until constant mass. After that, the iron content was determined.

Iron content determination. The dried samples of mycelial or vegetable biomass, or their enzymatic hydrolysates (supernatant or precipitate), were added to $\mathrm{HNO}_{3}$ (67\%), 1:12 (mass:volume), and each mixture was kept at $22 \pm 2{ }^{\circ} \mathrm{C}$ for $72 \mathrm{~h}$. Each mixture was heated at $100{ }^{\circ} \mathrm{C}$, and $\mathrm{H}_{2} \mathrm{O}_{2}(30 \%), 1: 6$ (mass:volume), was added. The volume was adjusted to $10 \mathrm{~mL}$ with ultrapure water. The iron content of the samples was determined by flame atomic absorption spectrophotometry (GBC model 932 plus). For iron content calculation, a calibration curve $\left(\mathrm{R}^{2}=0.998\right)$ was used with analytical standard, certified and traceable (GQ AA Lot 218410115 ultrascientific analytical solutions) with $0.01 \mu \mathrm{g} \mathrm{mL}^{-1}$ ion detection limit. In addition, for each batch of analyses, an internal standard was placed without the analytical ion and with the standard of the certified element.

The iron availability (\%) was calculated by dividing the solubilized iron from the sample by the total iron content in each sample. For fungi, the total iron transfer from the culture medium to the mycelial biomass was calculated by multiplying the mycelial biomass iron content by the mycelial biomass in each batch.

Statistical analysis. The experimental design was completely randomized, and the arithmetic averages and standard deviations calculated for four biological replicates. The results were submitted to distribution fitting, using maximum likelihood, a two-way ANOVA, and Tukey's HSD (honestly significant difference) test $(p \leq 0.05)$, utilizing the software XLSTAT version 2020.3 (https://www.xlstat.com/en/) and by Software Statistica 13.3 (StatSoft South America, Quest Software Inc, Ok, USA) Serial Number: JPZ711I235230FA-T. The statistical analysis of all data is available for consultation in the supplementary material 1, 2, and 3 .

Received: 5 February 2020; Accepted: 22 June 2020

Published online: 30 July 2020

\section{References}

1. Dunn, L. L., Rahmanto, Y. S. \& Richardson, D. R. Iron uptake and metabolism in the new millennium. Trends Cell Biol. 17, 93-100 (2007).

2. WHO-World Health Organization, Department of Nutrition for Health and Development. The global prevalence of anaemia in 2011. (WHO, Geneve, 2015). accessed 10 Oct 2019. https://apps.who.int/iris/bitstream/handle/10665/177094/9789241564960_eng. pdf?sequence $=1$.

3. Lopez, A., Cacoub, P., Macdougall, I. C. \& Peyrin-Biroulet, L. Iron deficiency anaemia. Lancet 387, 907-916 (2016). 
4. Premkumar, S., Ramanan, P. V. \& Thanka, J. Anaemia in school children-looking beyond iron deficiency. J. Evolut. Med. Dent. Sci. 7(45), 4884-4887 (2018).

5. WHO-World Health Organization, Department of Nutrition for Health and Development. Global nutrition targets 2025: Anaemia policy brief. (WHO, Geneve, 2014). accessed 10 Oct 2019. https://apps.who.int/iris/bitstream/handle/10665/148556/WHO_NMH_ NHD_14.4_eng.pdf?ua=1.

6. Blanco-Rojo, R. \& Vaquero, M. P. Iron bioavailability from food fortification to precision nutrition. A review. Innov. Food Sci. Emerg. Technol. 51, 126-138 (2019).

7. Vaquero, M. P., Garcia-Quismondo, A., Del Cañizo, F. J. \& Sanchez-Muniz, F. J. Iron status biomarkers and cardiovascular risk. In Recent Trends in Cardiovascular Risks (ed. Kumar, A.) 97-117 (IntechOpen, London, 2017).

8. Almeida, S. M. et al. Iron bioaccumulation in mycelium of Pleurotus ostreatus. Braz. J. Microbiol. 46, 195-200 (2015).

9. Yokota, M. E. et al. Iron translocation in Pleurotus ostreatus basidiocarps: Production, bioavailability, and antioxidant activity. Genet. Mol. Res. 15, gmr.15017888 (2016).

10. Umeo, S. H. et al. Iron and zinc mycelial bioaccumulation in Agaricus subrufescens strains. Semin. Cienc. Agrar. 40, 2513-2521 (2019).

11. Marcante, R. C. et al. Zinc bioaccumulation in Agaricus subrufescens mycelium. Arq. Cienc. Vet. Zool. Unipar 17, 249-252 (2014).

12. Niedzielski, P. et al. Supplementation of cultivated mushroom species with selenium bioaccumulation and speciation study. Eur. Food Res. Technol. 241, 419-426 (2015).

13. Faria, M. G. I. et al. Bioaccumulation of lithium $\left(\mathrm{Li}_{2} \mathrm{CO}_{3}\right)$ in mycelia of the culinary-medicinal oyster mushroom, Pleurotus ostreatus (Agaricomycetes). Int. J. Med. Mushrooms 20, 901-907 (2018).

14. Faria, M. G. I. et al. Lithium bioaccumulation in Lentinus crinitus mycelial biomass as a potential functional food. Chemosphere 235, 538-542 (2019).

15. DeMaeyer, E. M. et al. Preventing and controlling iron deficiency anaemia through primary health care: A guide for health administrators and programme managers (WHO, Geneva, 1989). accessed 10 Oct 2019. https://apps.who.int/iris/bitstream/handle/10665 139849/9241542497_eng.pdf?sequence=1\&isAllowed=y.

16. Jones, M. P. et al. Agricultural by-product suitability for the production of chitinous composites and nanofibers utilizing Trametes versicolor and Polyporus brumalis mycelial growth. Process Biochem. 80, 95-102 (2019).

17. CONAB-Companhia Nacional de Abastecimento, Ministério da Agricultura, Pecuária e Abastecimento do Brasil. Acompanhamento da safra brasileira de cana-de-açúcar, Vol. 6(2), safra 2019/20. (CONAB, Brasília, 2019). https://www.conab.gov.br/info-agro/ safras/cana/boletim-da-safra-de-cana-de-acucar.

18. Umeo, S. H. et al. Iron or zinc bioaccumulated in mycelial biomass of edible basidiomycetes. An. Acad. Bras. Cienc. 92 (2020) (in press).

19. Hass, H. Molecular genetics of fungal siderophore biosynthesis and uptake: the role of siderophores in iron uptake and storage. Appl. Microbiol. Biotechnol. 62, 316-330 (2003).

20. Haneef, M. et al. Advanced materials from fungal mycelium: Fabrication and tuning of physical properties. Sci. Rep. 7, 41292 (2017).

21. Kim, K. et al. Bioproduction of mushroom mycelium of Agaricus bisporus by commercial submerged fermentation for the production of meat analogue. J. Sci. Food Agric. 91(9), 1561-1568 (2011).

22. Valle, J. S. et al. Optimization of Agaricus blazei laccase production by submerged cultivation with sugarcane molasses. Afr. J. Microbiol. Res. 8, 939-946 (2014).

23. Marim, R. A. et al. Use of sugarcane molasses by Pycnoporus sanguineus for the production of laccase for dye decolorization. Genet. Mol. Res. 15, gmr15048972 (2016).

\section{Acknowledgements}

The authors thank Universidade Paranaense, Coordenação de Aperfeiçoamento de Pessoal de Nível Superior, Brazil (CAPES) - finance code 001-Fundação Araucária, and Conselho Nacional de Desenvolvimento Científico e Tecnológico $(\mathrm{CNPq})$ for the financial support and fellowship.

\section{Author contributions}

Paper conceived, designed and written by: G.A.L.; N.B.C.; and S.S.S. Data acquisition, analysis, and interpretation by: S.S.S.; M.G.I.F.; J.S.V.; A.C.G.; D.C.D.; L.G.V. Critical revision of the manuscript for important intellectual content: N.B.C. Research Project coordinator: G.A.L.

\section{Competing interests}

The authors declare no competing interests.

\section{Additional information}

Supplementary information is available for this paper at https://doi.org/10.1038/s41598-020-69699-0.

Correspondence and requests for materials should be addressed to G.A.L.

Reprints and permissions information is available at www.nature.com/reprints.

Publisher's note Springer Nature remains neutral with regard to jurisdictional claims in published maps and institutional affiliations.

Open Access This article is licensed under a Creative Commons Attribution 4.0 International License, which permits use, sharing, adaptation, distribution and reproduction in any medium or format, as long as you give appropriate credit to the original author(s) and the source, provide a link to the Creative Commons license, and indicate if changes were made. The images or other third party material in this article are included in the article's Creative Commons license, unless indicated otherwise in a credit line to the material. If material is not included in the article's Creative Commons license and your intended use is not permitted by statutory regulation or exceeds the permitted use, you will need to obtain permission directly from the copyright holder. To view a copy of this license, visit http://creativecommons.org/licenses/by/4.0/.

(C) The Author(s) 2020 